Process genre-based approach in improving the essay writing skills of grade 3 learners in a selected public elementary school towards a proposed PGB compendium

Relano, Catherine Q.

Emilio Aguinaldo College, Philippines (catherinerelano.mnl@eac.edu.ph)

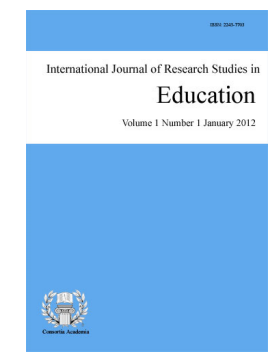

ISSN: $2243-7703$ Online ISSN: 2243-7711

Received: 30 March 2021

Revised: 18 May 2021 DOI: $10.5861 /$ ijrse. 2021.666

Accepted: 30 May 2021

OPEN ACCESS

\title{
Abstract
}

This study aimed to assess the effectiveness of the Process Genre-Based (PGB) Approach in improving the essay writing skills of Grade 3 learners in Cainta Elementary School using a quasi-experimental method that utilized the pre-test-post-test design. Two groups composed of 35 learners each served as experimental and control groups. The PGB approach was implemented on the experimental group using the proposed PGB compendium. A pre-test was conducted at the start of the experiment. It was given as a post-test at the end of the investigation. In addition, the researcher-developed instrument underwent validation. The test assessed the learners' writing in the content, organization, grammar, vocabulary, and mechanics using a 5-point rubric. Results of the study indicate that the experimental and control groups had comparable pre-test performance in the aspects of content, organization, grammar, vocabulary, and mechanics. Post-test results generally showed that the experimental group exhibited better performance levels than the control group in all aspects of writing. Statistical analysis, however, revealed that the experimental group performed significantly better in the areas of vocabulary and content. These results suggest that PGB can improve the pupils' writing skills, and its extensive use with appropriate teacher training is strongly recommended.

Keywords: process genre-based, essay writing skills, quasi-experiment, pre-test, post-test 


\section{Process genre-based approach in improving the essay writing skills of grade 3 learners in a selected public elementary school towards a proposed PGB compendium}

\section{Introduction}

Writing is one of the basic communication skills and learning to write modification and understanding just as working out as the same with all printed materials. Learners can develop their ability to write through the information and knowledge from what they read, heard, etc. They can compose words based on their intellectual capacity and understanding, and it is essential in writing. Nevertheless, although the student does not see each word, they hear new sounds, new words, and new expressions, which they would then be competent to give a try by replicating what they have heard. Learners' writing abilities are crucial to their academic achievements to get to the educational program and improve their correspondence and language aptitudes. Writing is the least expensive method for obtaining learning and subsequently enhancing their way of life.

Writing skills have a great impact and significance on the everyday life of every learner. Through writing, someone can express their thoughts, ideas, feelings, voice, and their interest. Given the high in resources, it is an impetus to develop the significance of writing programs to improve the student essay writing skills. The intention is that this will result in developing more innovative ideas and practices in combining proposed programs into better and more effective teaching of writing in school. Moreover, this study is undertaken to provide some basis for using writing programs or looking for better alternatives to boost the students' essay writing skills. The advantages that come from well-created writing skills are interminable. Essay writing skills will help a child in an English class and every aspect of academic study.

This research is focused on the theoretical framework for writing by Derewianka (2007). As per this theory, this agreeable consistency was disturbed in the late 1970s with the development of 'process writing.' The theory proposes that students be allowed to pick anything they desire to write about, finding what they need to state in the demonstration of writing (Graves, 1983). The subsequent diagram has been tailored from Derewianka (2007).

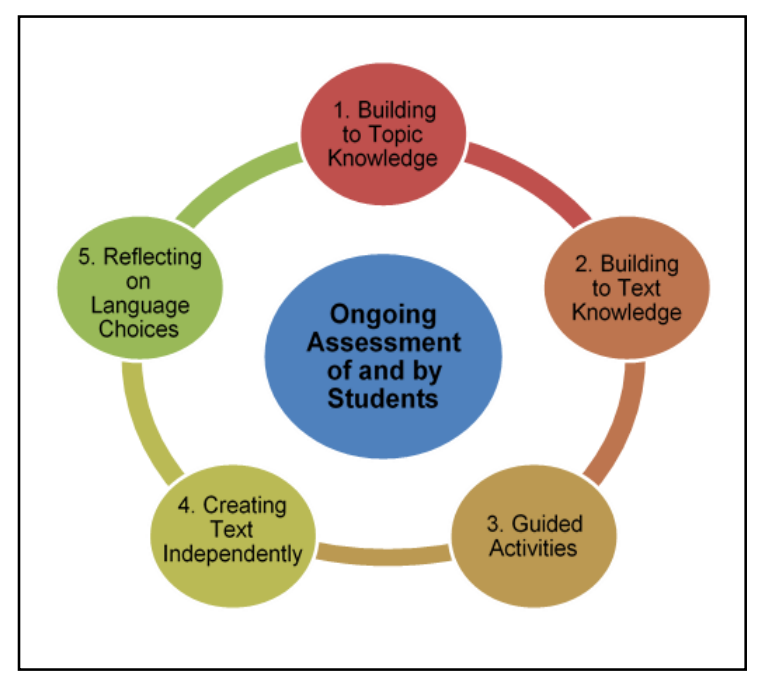

Figure 1: Theoretical Framework for Writing

The first step in writing a paper is to develop subject ideas and a chart of keywords and terms. Second, to learn about the subject from among all the obvious choices. Next, the main goals are to encourage learners to hear, see, read, and write the target language. Autonomous text is then, which provides a set of rubrics to learners, 
so they know what they need to say and how well they need to do. Lastly, students must be able to read their writing aloud before a final examination. Feedback is also required.

\subsection{Significance of the Study}

In due consideration of the significance of why the study needs to be investigated, the researcher finds that this academic endeavor will benefit school administrators. In addition, the result of the study will be used as a frame of reference in discovering ways to improve teaching how to write.

The study results will aid as the model and step in streamlining the curriculum, especially in the writing strategies area, which will solve the needs of the stimulating times and develop students' essay writing that will make them even more productive.

It will serve as a revelation for English teachers to realize their vital role in providing quality education to the country's youth. Furthermore, this makes them recognize the new methods in teaching writing and policies and practices in implementing writing programs, which may subsidize optimal learning among their learners by focusing on the students' writing skills.

This study will pave the way towards the realization of parents' important role in providing their children with an atmosphere that will foster a positive outlook towards writing. This will also help them recognize their part in ensuring the better schooling of their children by providing the proper supply of necessary materials and tools for their children's welfare and continuous development in essay writing skills.

Participants will be the most benefited by this study as whatever developments for improvement that administrators and faculty may do will be for their future opportunities as productive and worthy citizens of the community. In addition, this will help them broaden their appreciation in enhancing their essay writing skills and provide them with the best-suited writing programs.

The thoughts on this learning will help future researchers elevate their literature in the same field of research. In addition, this may add to their enthusiasm to conduct a study along with essay writing skills, strategies, and writing programs.

\section{Methodology}

The study utilized the quasi-experimental examination, anchored on exploring the impacts of embracing a process genre-based approach to essay guidance in learning circumstances. Consequently, the study's discoveries ought to be deciphered in the context of the experimental conditions. The investigation includes express guidance in process genre-based writing techniques that envelop the whole forming process to chosen pupils whose ages extend between 8-10 years of age. Because of time limitations, the subjects were restricted to thirteen sessions of eighty minutes of guidance, which added a successful aggregate of twenty hours of guidance.

The researcher utilized purposive sampling wherein selected elementary pupils in 17 sections of Grade Three in Cainta Elementary School were the study respondents. Therefore, based on the data given by Cainta Elementary School, there were 17 sections in grade 3 level with a total population of 633 pupils. The participant of the study is composed of 70 pupils. The researcher obtained the respondents from a wide range of participants, which helped enrich the research data. Two treatment groups were assigned to the topics: (1) an experimental group with genre-based writing instructions and (2) a control group with traditional writing instructions. Each group assigned was cared for 80 minutes. The subjects have been tested before and after treatment.

Pre-test and post-test were employed. Writing a descriptive essay about the chosen topic was used to quantitatively measure pupils' writing ability in terms of content, organization, grammar, vocabulary, and mechanics. The essay length is about 80 to 150 words of at least three paragraphs for pre-test and post-test. The time allotted for both tests is 80 minutes. The topics given for the pre-test and post-test are suited to the level of 
Relano, C. Q.

primary learners. Checking of the outputs are based on the rubrics of criteria as follows: 1.00-1.49 (Not complete component), 1.50-2.49 (Fairly complete component), 2.50-3.49 (Equally complete component), 3.50-4.49 (Nearly complete component), 4.50-5.00 (Complete component).

In the formulation of the test, the researcher considered some sources like writing books of local and foreign writers and master's thesis, which had bearings on the present study. Furthermore, the test utilized by the researcher in her research literature served as her reference in preparing her first draft. The prepared test was referred to the writer's adviser for suggestions and criticisms. Some suggestions were incorporated into the test. After including some suggestions and some corrections made, the final draft was made. So, the final copies of the test were then prepared.

After the approval, the researcher secured a permit from the Schools Division Office of Rizal for the administration. The administration of the tests and their collection flowed smoothly to ensure the best result of the study. After that, the results were formulated and interpreted using data analysis. Through this, the researcher arrived at the interpretation and discussion of the results. The respondents were briefed about the nature and purpose of the research and subsequently given eighty minutes to answer the pre-test. Finally, the schedule for the administration of the instrument was arranged, set, and confirmed. The evaluation of the quantitative data gathered through the tests was collected, tabulated, computed, and processed using the Statistical Packages for Social Sciences Version 24 software. The results were interpreted and used to analyze the objectives and questions of the study.

The data collected through the essay writing test were analyzed using the Quasi-Experimental Design, Frequency Distribution, Mean, Standard Deviation, and T-test. Careful application statistical measurement on the research output's validity and reliability were made to ensure the accuracy of the results. Finally, the findings were summarized and compared with each work; conclusions were drawn, and recommendations were formulated.

\section{Findings and Discussion}

The data and its analysis and interpretation are provided below to provide the answers to the problems in this study.

What are the pre-test and post-test scores of the learner-subjects in the control and experimental groups?

\section{Table 1}

Frequency, percentage, and composite mean scores in pre-test of the control and experimental groups

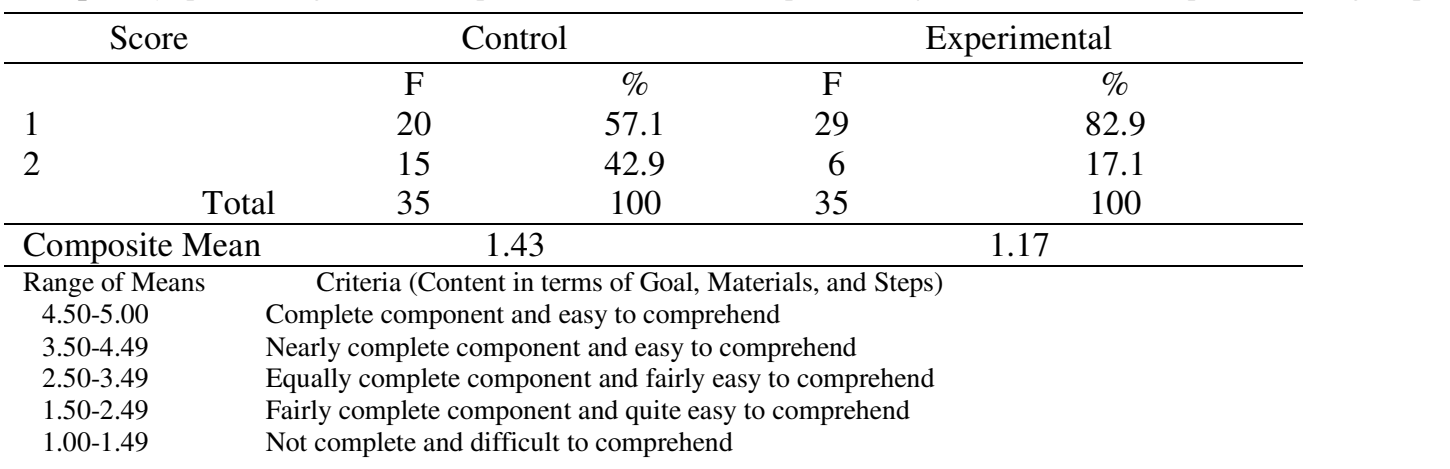

The table above reveals that in the aspect of content, the control group obtained a mean score of 1.43 while the experimental group obtained 1.17. Thus, based on the scoring rubric, the work of both groups is "not complete and difficult to comprehend." This implies that the performance of both groups is comparable at the start of the experiment. 
Process genre-based approach in improving the essay writing skills of grade 3 learners

Table 2

Frequency, percentage, and composite mean scores in post-test of the control and experimental groups

\begin{tabular}{lccccc}
\hline & Scores & & Control & \multicolumn{2}{c}{ Experimental } \\
\hline & $\mathrm{F}$ & $\%$ & $\mathrm{~F}$ & $\%$ \\
2 & 24 & 68.6 & 0 & 0 \\
3 & 11 & 31.4 & 0 & 0 \\
4 & & 0 & 0 & 15 & 42.9 \\
5 & & 0 & 0 & 20 & 57.1 \\
& Total & 35 & 100 & 35 & 100 \\
\hline Composite Mean & & 2.31 & \multicolumn{3}{c}{4.57} \\
\hline
\end{tabular}

The table above reveals that in the post-test, the control group obtained a mean score of 2.31, which means that their work "provides a fairly complete component and quite easy to comprehend." The experimental group's mean score is 4.57 , which means that the group's work provides a complete component and easy to comprehend. The treatment group was stronger than the control group. This suggests that the PGB method can be attributed to the better performance of the experimental group.

\section{Table 3}

Frequency, percentage, and composite mean scores in pre-test of the control and experimental groups

\begin{tabular}{|c|c|c|c|c|c|}
\hline \multicolumn{2}{|c|}{ Scores } & \multicolumn{2}{|c|}{ Control } & \multicolumn{2}{|c|}{ Experimental } \\
\hline & & $\mathrm{F}$ & $\%$ & $\mathrm{~F}$ & $\%$ \\
\hline 1 & & 24 & 68.6 & 30 & 85.7 \\
\hline \multirow[t]{2}{*}{2} & & 11 & 31.4 & 5 & 14.3 \\
\hline & Total & 35 & 100 & 35 & 100 \\
\hline Composite Mean & & 1.31 & & 1. & \\
\hline Range of Means & \multicolumn{5}{|c|}{ Criteria (Organization of Content) } \\
\hline $4.50-5.00$ & \multicolumn{5}{|c|}{ Well-organized and use effective transitional words/phrases. } \\
\hline $3.50-4.49$ & \multicolumn{5}{|c|}{ Fairly well organized and use effective transitional words/phrases. } \\
\hline $2.50-3.49$ & \multicolumn{5}{|c|}{$\begin{array}{l}\text { Roughly organized, but main ideas are clear, logical but inadequate transitional } \\
\text { words/phrases. }\end{array}$} \\
\hline $1.50-2.49$ & \multicolumn{5}{|c|}{ Disconnected ideas and lack of transitional words/phrases } \\
\hline $1.00-1.49$ & \multicolumn{5}{|c|}{ Lacking in an organization and uses no transitional words/phrases } \\
\hline
\end{tabular}

The table above reveals that in the pre-test, the control group obtained 1.31 while the experimental group obtained a composite mean score of 1.14. Both scores mean that in terms of organization, the pupils' writing lacks organization and does not use appropriate transitional words and phrases. This implies that at the start of the experiment, both groups have a similar level of performance. Table 4 below reveals the post-test performance of both groups in the writing aspect of the content organization. The mean performance of the experimental group is markedly increased compared to the control group. The experimental group has well-organized its work with a mean score of 4.54 and uses suitable transitional devices. In comparison, the average score of the group control is only 2.57 , suggesting that their work has become rough, but the key concepts are rational and logical. In contrast, transitional words and sentences have not been used.

\section{Table 4}

Frequency, percentage, and composite mean scores in post-test of the control and experimental groups

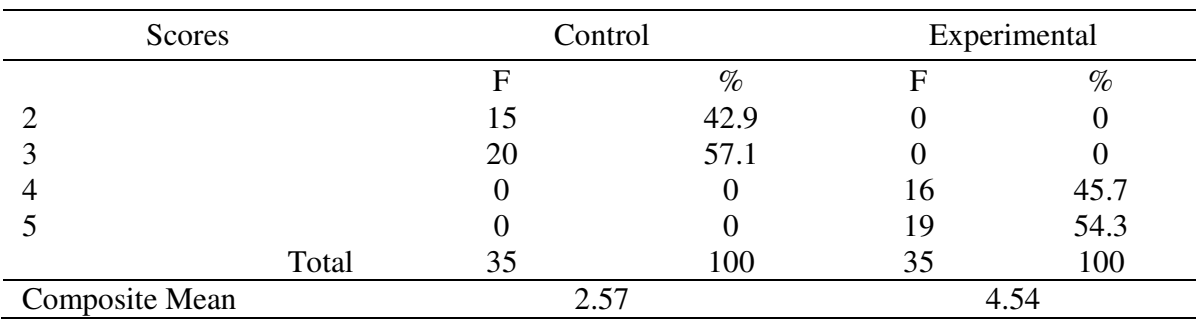

This indicates that the experimental group was stronger than the control group and can be due to the PGB written method. 
Relano, C. Q.

\section{Table 5}

Frequency, percentage, and composite mean scores in pre-test of the control and experimental groups

\begin{tabular}{lccccc}
\hline & Scores & Control & & Experimental \\
\hline & & $\mathrm{F}$ & $\%$ & $\mathrm{~F}$ & $\%$ \\
2 & 8 & 22.9 & 21 & 60.0 \\
3 & 26 & 74.3 & 14 & 0 \\
& & 2.9 & 0 & 100 \\
\hline Composite Mean & Total & 35 & 100 & 35 & \\
\hline Range of Means & Criteria (Grammar in terms of Parts of Speech) & & \\
$4.50-5.00$ & No errors seen using the parts of speech & & \\
$3.50-4.49$ & Slightly no errors using the parts of speech & & \\
$2.50-3.49$ & Some errors using the parts of speech & & \\
$1.50-2.49$ & Many errors using the parts of speech & & \\
$1.00-1.49$ & Dominated by errors with no mastery of the parts of speech
\end{tabular}

In terms of sections of expression, the table above presents the pre-test scores of the control and experimental groups in the field of grammar. The control group obtained a mean score of 1.80 which means that their writing contains many errors in the use of parts of speech. The experimental group obtained a mean score of 1.40 which means that their work is dominated by errors indicating a lack of mastery of parts of speech. These findings indicate that the control group at the beginning of the experiment is a stage higher than the experimental group.

Table 6

Frequency, percentage, and composite mean scores in post-test of the control and experimental groups

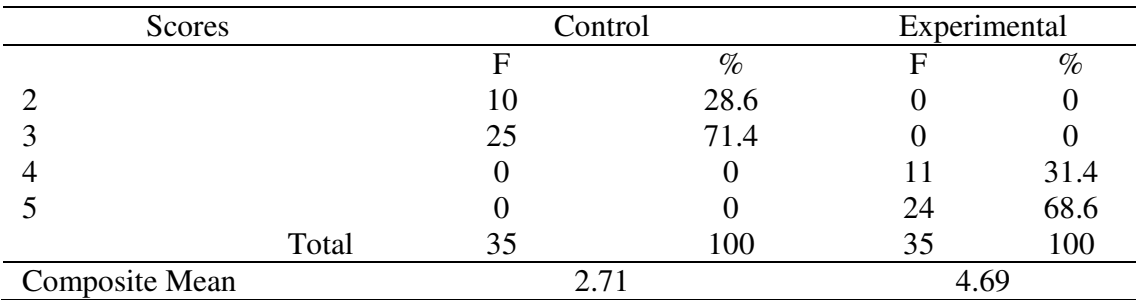

In terms of sections of expression, the table above shows the post-test success of the two classes in the writing element of grammar. A mean score of only 2.71, suggesting some errors in the use of parts of an expression, as reported by the control group. Nevertheless, the experimental group obtained a mean score of 4.69, suggesting very limited to no errors in their writing in terms of parts of speech. Thus, the study team performed much better than the control group. This suggests that the use of the PGB writing method is due to the increase in the experimental group's performance.

\section{Table 7}

Frequency, percentage, and composite mean scores in pre-test of the control and experimental groups

\begin{tabular}{|c|c|c|c|c|c|}
\hline \multirow[t]{2}{*}{ Score } & & \multicolumn{2}{|c|}{ Control } & \multicolumn{2}{|c|}{ Experimental } \\
\hline & & $\mathrm{F}$ & $\%$ & $\mathrm{~F}$ & $\%$ \\
\hline 1 & & 16 & 45.7 & 32 & 91.4 \\
\hline 2 & & 18 & 51.4 & 3 & 8.6 \\
\hline 3 & & 1 & 2.9 & 0 & 0 \\
\hline & Total & 35 & 100 & 35 & 100 \\
\hline Composite Mean & & \multicolumn{2}{|c|}{1.57} & \multicolumn{2}{|c|}{1.09} \\
\hline Range Of Means & \multicolumn{5}{|c|}{ Criteria (Vocabulary - Selection Of Words And Word Forms) } \\
\hline $4.50-5.00$ & \multicolumn{5}{|c|}{ Very Effective Selection Of Words And Word Forms } \\
\hline $3.50-4.49$ & \multicolumn{5}{|c|}{ Effective Selection Of Words And Words Forms } \\
\hline $2.50-3.49$ & \multicolumn{5}{|c|}{ Satisfactory With Some Misuse Of Vocabulary And Word Forms } \\
\hline $1.50-2.49$ & \multicolumn{5}{|c|}{ Jumbled Use Of Words And Word Forms In A Limited Range } \\
\hline $1.00-1.49$ & \multicolumn{5}{|c|}{ Very Poor Knowledge And Very Limited Range } \\
\hline
\end{tabular}

In the writing element of vocabulary, the table above illustrates the pre-test scores of the control and experimental classes. The control group obtained a mean score of 1.57 . This implies that the jumbled use of 
terms and word types in their writing reflects a restricted range of information. In contrast, the experimental group obtained a mean score of 1.09 , indicating very poor knowledge and very limited knowledge of words and word forms. These results suggest that the two groups have close writing abilities at the start of the experiment.

\section{Table 8}

Frequency, percentage, and composite mean scores in post-test of the control and experimental groups

\begin{tabular}{|c|c|c|c|c|}
\hline Score & \multicolumn{2}{|c|}{ Control } & \multicolumn{2}{|c|}{ Experimental } \\
\hline & $\mathrm{F}$ & $\%$ & $\mathrm{~F}$ & $\%$ \\
\hline 2 & 12 & 34.3 & 0 & 0 \\
\hline 3 & 23 & 65.7 & 0 & 0 \\
\hline 5 & 0 & 0 & 35 & 100.0 \\
\hline Total & 35 & 100 & 35 & 100 \\
\hline Composite Mean & \multicolumn{2}{|c|}{2.66} & \multicolumn{2}{|c|}{5.00} \\
\hline
\end{tabular}

Table 8 shows the post-test scores of the control and experimental classes in the writing element of vocabulary. The control group achieved a mean score of 2.66, suggesting that their writing improved to a satisfactory degree, albeit with some abuse of vocabulary terms and word types. However, the experimental group obtained a mean score of 5.00, suggesting that they have become very successful in their selection of words and word forms. The output of the experimental group is still a lot higher than the control group. These findings indicate that the PGB method of writing can be related to the improved performance of the experimental community.

\section{Table 9}

Frequency, percentage, and composite mean scores in pre-test of the control and experimental groups

\begin{tabular}{|c|c|c|c|c|c|}
\hline \multirow[t]{2}{*}{ Scores } & & \multicolumn{2}{|c|}{ Control } & \multicolumn{2}{|c|}{ Experimental } \\
\hline & & $\mathrm{F}$ & $\%$ & $\mathrm{~F}$ & $\%$ \\
\hline 1 & & 12 & 34.3 & 31 & 88.6 \\
\hline 2 & & 18 & 51.4 & 4 & 11.4 \\
\hline 3 & & 5 & 14.3 & 0 & 0 \\
\hline & Total & 35 & $\mathrm{H}$ & 035 & 100 \\
\hline Composite Mean & \multicolumn{3}{|c|}{1.80} & \multicolumn{2}{|c|}{1.11} \\
\hline Range Of Means & \multicolumn{5}{|c|}{ Criteria (Mechanics - Punctuation And Capitalization) } \\
\hline $4.50-5.00$ & \multicolumn{5}{|c|}{ Well-Organized In Using Punctuation And Capitalization } \\
\hline $3.50-4.49$ & \multicolumn{5}{|c|}{ Organized In Using Punctuation And Capitalization } \\
\hline $2.50-3.49$ & \multicolumn{5}{|c|}{ Occasional Errors In Using Punctuation And Capitalization } \\
\hline $1.50-2.49$ & \multicolumn{5}{|c|}{ Frequent Errors In Using Punctuation And Capitalization } \\
\hline $1.00-1.49$ & \multicolumn{5}{|c|}{ Dominated By Errors In Using Punctuation And Capitalization } \\
\hline
\end{tabular}

Table 9 above shows the pre-test scores of the participating groups in the writing aspect of mechanics in terms of the proper use of punctuation and capitalization. The control group obtained a mean score of 1.80 which means that their writing frequently contains errors in punctuation and capitalization. The experimental group obtained a lower mean of 1.11, indicating that their world is riddled or dominated with errors in punctuation and capitalization. These results suggest that the control group has a slightly higher ability level than the experimental group at the start of the experiment.

Table 10

Frequency, percentage, and composite mean scores in post-test of the control and experimental groups

\begin{tabular}{lcccc}
\hline Mechanics Post-Test & \multicolumn{2}{c}{ Control } & \multicolumn{2}{c}{ Experimental } \\
\hline Score & $\mathrm{F}$ & $\%$ & $\mathrm{~F}$ & $\%$ \\
2 & 15 & 42.9 & 0 & 0 \\
3 & 13 & 37.1 & 0 & 0 \\
4 & 7 & 20.0 & 0 & 0 \\
5 & 0 & 0 & 35 & 100 \\
& & 100 & 35 & 100 \\
\hline Composite Mean & Total & 35 & \multicolumn{2}{c}{5.0} \\
\hline
\end{tabular}

The above table presents the control and experimental groups' post-test scores in the mechanic's aspect. The 
Relano, C. Q.

control group received 2.77, showing that occasional errors in punctuation capitalization mark their mechanics. However, to achieve a perfect mean score, which reflects well-organized use of punctuation and capitalization, the experimental group performed much better than the control group. These findings suggest that the PGB approach is more successful in improving the mastery of mechanics of the pupils than the traditional teaching process.

Table 11

Over-all frequency, percentage, and composite mean scores in pre-test of the control and experimental groups

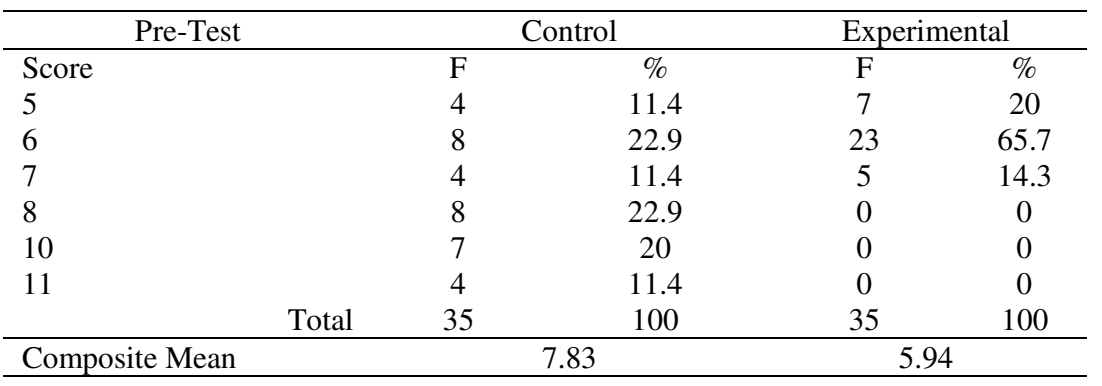

The average frequency and percentage distribution of pre-test scores of the subjects in the control and experimental groups with a combined mean of 7.83 and 5.94 are shown in Table 11 for the control and experimental groups. Data reveals that during the pre-test, respondents from experimental and control groups had poor results.

Table 12

Over-all frequency, percentage, and composite mean scores in posttest of the control and experimental groups

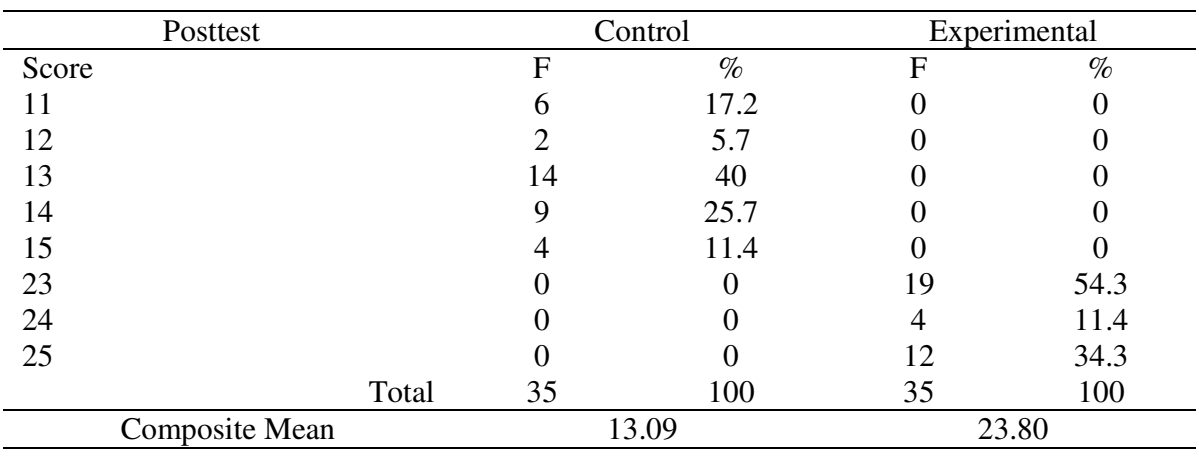

Using the traditional and PGB method, Table 12 displays the average frequency and percentage distribution of post-test scores of subjects in the control and experimental groups with a combined mean of 13.09 and 23.80. Data proves that control and experimental groups have improved their efficiency. However, there is a higher post-test score ranking for the experimental group than for the control group. Similarly, Rutherford (2016) stressed that writing includes knowledge of the language. The development of the word takes place through the development of the students' skills and feedback.' Given this, the process genre-based approach is favorable for written classes in the modern classroom. This approach involves some critical elements of alternative or more traditional writing approaches, the assessment of model text, the planning and drawing processes (as is the methodology), and the provision of knowledge to students (as like the genre approach).

\section{Is there a significant difference between the pre-test and post-test scores of both groups?}

An independent t-test was carried out to compare the scores of the control and experimental groups to address this problem. The significance level alpha is set at 0.05 . $p$-values greater than 0.05 show a significant difference, while those below 0.05 show no significant difference. 
Table 13

T-test results of the comparison of the pre-test scores of control and experimental groups

\begin{tabular}{|c|c|c|c|c|c|c|c|}
\hline & $\mathrm{N}$ & Mean & $\begin{array}{l}\text { Std. } \\
\text { dev. }\end{array}$ & $\begin{array}{c}\text { Computed } \\
\text { t-Value }\end{array}$ & P-Value & Decision & Interpretation \\
\hline Control Group & 35 & 7.83 & 1.99 & \multirow[b]{2}{*}{-5.368} & \multirow[b]{2}{*}{0.000001} & \multirow[b]{2}{*}{ Reject Ho } & \multirow[b]{2}{*}{ Significant } \\
\hline $\begin{array}{l}\text { Experimental } \\
\text { Group }\end{array}$ & 35 & 5.94 & 0.59 & & & & \\
\hline
\end{tabular}

Based on the table above, with at-value $=-5.368$ and $p$-value $=0.000001$, which is lower than 0.05 , there is a significant difference between the mean scores of the experimental and control groups pre-test. The null hypothesis is, thus, denied. In other words, it is not comparable to the output of the control and experimental classes.

\section{Table 14}

T-test results of the comparison of the post-test scores of control and experimental groups

\begin{tabular}{lccccccc}
\hline & $\mathrm{N}$ & Mean & $\begin{array}{c}\text { Std. } \\
\text { Dev. }\end{array}$ & $\begin{array}{c}\text { Computed } \\
\text { t-Value }\end{array}$ & P-Value & Decision & Interpretation \\
\hline Control Group & 35 & 13.09 & 1.22 & \multirow{2}{*}{41.234} & .000007 & Reject Ho & Significant \\
\hline Experimental Group & 35 & 23.80 & 0.93 & & 0.93 \\
\hline
\end{tabular}

Table 14 above displays the results of the t-test analysis of the scores of the group. There is a substantial difference between the mean scores of the control and the experimental groups in the post-test with a t-value $=$ 41.234 and a $p$-value $=.000007$, which is less than 0.05 . This indicates that, as a result of the PGB approach used to teach them, the experimental group performed substantially better than the control group in their writing.

Also, Roseberry (2018), a Brunei-based project, is particularly enthralling. They found that the test group (using a genre-based methodology) outperformed the control group (using a non-genre-based methodology) in terms of writing results, demonstrating a superior understanding of both expository structure and phonetic features.

\section{What are the observed behaviors of the learners during the implementation of the PGB approach?}

Few learners avoided writing and felt nervous at the start, while most of them looked forward to writing down their ideas. Some have no fear that their writing is being evaluated. They like seeing their thoughts on paper and enjoyed submitting their essays to the teacher for evaluation.

$>\quad$ The learners wanted to get more feedback from the teacher for the corrections of their essays.

$>\quad$ They used freewriting as a planning strategy in writing.

$>\quad$ They used more than three drafts in writing their essays.

$>$ Revising and editing their written works helped them improve their writings.

$>\quad$ They were competent and confident to articulate their ideas clearly in prose.

$>\quad$ They want their readers to study what they wrote, particularly when they read their essays.

$>\quad$ Discussing their writings with others was an enjoyable experience.

$>\quad$ Writing an essay had been an interesting experience for the learners. They were satisfied and proud of their essays. 
What output may be proposed based on enhancing the essay writing skills of Grade 3 learners?

\section{Process Genre-Based Compendium (sample) Lesson Plan in English 3}

\section{Day 1 (80 minutes)}

I. Objective: Use descriptive and limiting adjectives in meaningful sentences.

\section{Subject Matter}

Descriptive and Limiting Adjectives

Reference: Linkages for Excellence 3, pp. 93 and 97

Materials: PowerPoint presentation and worksheets

\section{Ill. Learning Activities}

\section{A. Motivation}

Gather the class in any part of the school. Encourage them to list down and describe the things they see.

\section{B. Presentation}

Group Activity - Let us gather all your answers per group. Then, write them in the table below.

\begin{tabular}{|l|l|}
\hline Things & Description \\
\hline & \\
\hline & \\
\hline & \\
\hline & \\
\hline & \\
\hline
\end{tabular}

\section{Discussion}

Explanation of grammar concept on descriptive and limiting adjectives

\section{Generalization}

What are adjectives? What are two kinds of adjectives? When do we use descriptive adjectives?

When do we use limiting adjectives?

\section{E. Application}

Use the given phrase in a meaningful sentence.

1. third group

2. an octopus

3. eight books

4. this magazine

5. those balloons

\section{Evaluation}

Use the following phrases in meaningful sentences.

1. a blind man

2. the favorite movie

3. the responsible child

82 Consortia Academia Publishing (A partner of Network of Professional Researchers and Educators) 

4. those fresh vegetables
5. an expensive magazine

\section{Assignment}

Use the following descriptive or limiting adjectives in meaningful sentences.

1. a

2. these

3. honest

4. colorful

5. rectangular

\section{Recommendations}

The following recommendations are at this moment offered:

$>$ Provide extensive training and/or re-tooling teachers in the proper implementation of the PGB approach to Grade 3 learners.

$>$ Provide proper orientation on the PGB method to prepare the students for its unique process-based aspects.

$>$ Consider the emotional aspect of writing and provide the necessary psychological support to help students overcome their fear of failure, hesitations, doubts, and the like.

$>\quad$ Identify and exhibit model essays resulting from the implementation of PGB to provide the class with writing exemplars and recognition for "good writers."

$>\quad$ Conduct further experiments on PGB using a bigger sample and utilizing other research methods and techniques.

\section{Conclusion}

\section{What are the pre-test and post-test scores of the learner-subjects in the control and experimental groups?}

In terms of content, the control group improved from a pre-test mean of 1.43 to a post-test mean of 2.31, while the experimental group improved from a pre-test mean of 1.17 to 4.57 . This means the PGB method can be attributed to the enhanced success of the experimental team. The experimental group improved from a pre-test mean score of 1.14 to a post-test score of 4.54 in terms of organization, while the control group improved from a mean score of 1.31 to 2.57 . This means the PGB method can be attributed to the enhanced success of the experimental group. The control group progressed from a pre-test mean score of 1.80 to a post-test score of 2.71 in terms of grammar, while the experimental group increased from a mean score of 1.40 to 4.69 . This suggests the use of the PGB writing method is due to the increase in the performance of the experimental community.

The control group improved from a mean of 1.57 to 2.66 in the vocabulary portion, while the experimental group improved from a mean score of 1.09 to 5.0. These findings indicate that the PGB method of writing can be related to the improved performance of the experimental community. The control group improved a mean score of 1.80 to 2.77 in the mechanic's aspect, while the experimental group increased from a mean of 1.11 to 5.0. These findings suggest that the PGB approach is more successful in improving the mastery of mechanics of the 
Relano, C. Q.

pupils than the traditional teaching process.

\section{Is there a significant difference between the pre-test and post-test scores of both groups?}

There is an important disparity between the mean scores of the experimental and control groups in the pre-test. The null hypothesis is, thus, denied. At the start of the experiment, the control group performed better than the experimental group. There is a considerable gap between the mean scores of the post-test experimental and control classes. The null hypothesis is therefore ignored. As a consequence of the PGB method used to teach them, the experimental group performed substantially better than the control group in their writing.

Acknowledgments - The success of this study required the help of various individuals. Without them, the researcher might not meet her objectives in doing this study. Therefore, the researcher wants to give gratitude to the Almighty God first and foremost for giving her wisdom and strength to make this study possible. Second, to the school head and learner respondents in Cainta Elementary School, their cooperation and meaningful responses during this study. Finally, the researcher would like to express her profound gratitude to her parents, husband, child, sisters, and colleagues, who have provided her moral and emotional support. This accomplishment would not have been possible without them.

\section{References}

Derewianka, B. (2007). The contribution of genre theory to literacy education in Australia. University of Wollongong Australia.

Graves, Á. (1983). La argumentación escrita [Written argumentation]. Medellín, CO: Editorial Universidad de Antioquia.

Roseberry, L. (2018). The backwash effect: From testing to teaching. English Language Teaching Journal, 21(1), $1-25$.

Rutherford, P. (2016). Situating ESL writing in a cross-disciplinary context. Written Communication, 15(1), 19-121.

Weaver, L. (1990). English proficiency index (3rd ed.). México, MX: Author. 